\title{
Triple Carcinomas of the Breast in a Developing Community
}

\author{
Wilson IB Onuigbo* \\ Department of Pathology, Medical Foundation and Clinic, Nigeria
}

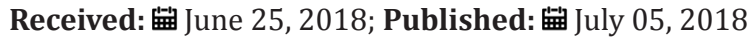

*Corresponding author: Wilson IB Onuigbo, Department of Pathology, Medical Foundation and Clinic, 8 Nsukka Lane, Enugu 400001, Nigeria

\begin{abstract}
A Glasgow Hospital was recorded for its preeminence in surgical pathology training. Its head's biography was on record also. More recently, a lecturer there co-authored a case of breast cancer with 3 histological types. Fortunately, he took great interest in my training as I acknowledged in publishing a triple lung cancer case. Therefore, I propose to document such triple breast carcinomas gathered from my Ibo/Igbo ethnic group thanks to using a Birmingham (UK) group's advice that instituting a histopathology data pool favors epidemiological analysis. Twenty-four cases are presented here in order to add to the world literature. Among the findings is that different quadrants need not be invoked, seeing that even a microscope slide may reveal up to three different types.
\end{abstract}

Keywords: Glasgow; Research; Training; Breast; Carcinoma; Triple Type; Developing Community

\section{Introduction}

The development of surgical pathology nicely took place during the latter part of the $19^{\text {th }}$ Century [1]. What occurred during it and the present century was fully publicized as regards the Glasgow Western Infirmary [2]. Fortunately, since I was trained there, I wrote on its first great name, Joseph Coats (1846-99), in 1970 [3]. Moreover, Andrew Sandison, who helped me greatly there, was much excited on publishing a triple case of breast carcinoma [4]. Little wonder that from there I personally published a triple case of lung cancer [5]. This trend was pursued on returning to my home country, Nigeria, especially as regards the Ethnic Group, Ibos/ Igbos [6]. Furthermore, having been stimulated by a Birmingham (UK) group concerning how the establishment of a histopathology data pool could promote epidemiological analysis "[7], this" paper analyzes my experience of using such a tool on breast cancers. In particular, the occurrence of triple tumors in this organ is deemed to be worthy of documentation. Although multiplicity may be thought of in terms of the quadrants of the breast, it is noteworthy that a single microscope slide may exhibit up to three distinguishable carcinomas.

\section{Investigation}

From 1970, the author, as Head of the Regional Pathology Laboratory established at Enugu by the Eastern Region of Nigeria Government, began to collect surgical specimens from numerous doctors working in several hospitals. The very serious stipulation was that, in sending the formalinized specimens, they must be accompanied by Request Forms which are filled properly. The accumulated records dealing with the breast are analyzed here as a contribution to world literature with reference to patients exhibiting three different types of carcinomas (Tables 1 \& 2).

Table 1: Epidemiological data on breast cancers exhibiting 3 types in a developing community.

\begin{tabular}{|c|c|c|c|c|c|c|c|}
\hline S/No. & Lab. No & Initials & Age & Site & Town & Doctor & Types \\
\hline 1 & UH 837/90 & ON & 38 & $\mathrm{~L}$ & Enugu & Ojukwu & Id,Il,Ac \\
\hline 2 & UH 1264/90 & UC & 45 & $\mathrm{~L}$ & Enugu & Udeh & $\mathrm{Id}, \mathrm{Mu}, \mathrm{Sq}$ \\
\hline 3 & UH 2064/90 & MT & 30 & $\mathrm{~L}$ & Enugu & Uche & $\mathrm{Ac}, \mathrm{Pa}, \mathrm{Mu}$ \\
\hline 4 & $546 / 91$ & $\mathrm{NI}$ & 37 & $\mathrm{R}$ & $\mathrm{PH}$ & Ezike & Id,Il,Me \\
\hline 5 & 9403227 & IC & 41 & $\mathrm{~L}$ & Umuahia & Ojukwu & $\mathrm{Il}, \mathrm{Co}, \mathrm{Ac}$ \\
\hline 6 & 9404170 & IP & 65 & $\mathrm{~L}$ & Aba & Ezebuike & Me,Co,Id \\
\hline 7 & 9406144 & UF & 45 & $\mathrm{~L}$ & Enugu & Ojukwu & Mi,Id,Il \\
\hline 8 & 940717 & IF & 43 & $\mathrm{~L}$ & Enugu & Ojukwu & Id,Il,Co \\
\hline 9 & 9407138 & OT & 40 & $\mathrm{R}$ & Enugu & Jiburum & Id,Il,Co \\
\hline 10 & 9409154 & NV & 46 & $\mathrm{~L}$ & Enugu & Okwulehie & Co,Il,Id \\
\hline
\end{tabular}




\begin{tabular}{|c|c|c|c|c|c|c|c|}
\hline 11 & 950128 & NO & 60 & L & Enugu & Ojukwu & Il,Ac,Id \\
\hline 12 & 9502101 & IC & 34 & R & Enugu & Ojukwu & Ac,Mu,Il \\
\hline 13 & 9502103 & EC & 57 & L & Enugu & Ojukwu & Il,Id,Pa \\
\hline 14 & 9510133 & IT & 45 & L & Enugu & Ilouga & Id,Il,Me \\
\hline 15 & 9601109 & OF & 39 & L & Owerri & Nkire & Id,Co,Mu \\
\hline 16 & 960489 & EP & 53 & L & Enugu & Udeh & Co,Id,Me \\
\hline 17 & 961298 & CO & 36 & R & Amaigbo & Liman & Id,Ac,If \\
\hline 18 & 9705114 & MC & 60 & R & Ojukwu & Id,Il,If \\
\hline 19 & 970867 & OJ & 65 & Enugu & Ojukwu & Ac,Id,Il \\
\hline 20 & 971077 & OC & 50 & Umuahia & Mbanaso & Ac,Co,Id \\
\hline 21 & 990243 & WN & 48 & L & Enugu & Ojukwu & Id,Ac,Pa \\
\hline 22 & 990243 & WN & 48 & Lnugu & Ojukwu & Id,Ac,Pa \\
\hline 23 & 990284 & OR & 35 & L & Enugu & Ojukwu & Id,Mu,Ac \\
\hline 24 & 99076 & UC & 60 & L & Enugu & Ezegwui & Mu,Ac,If \\
\hline
\end{tabular}

List of abbreviated diagnoses in alphabetical order.

Ac - Adenoid cystic

Cc - Clear cell

Co - Comedo

Id - Invasive ductal

Il - Invasive lobular

If - Inflammatory

Me - Medullary

$\mathrm{Mu}$ - Mucinous

Pa - Papillary

Sq - Squamous

Table 2: Age pattern of the affected women.

\begin{tabular}{|c|c|}
\hline Age & Number \\
\hline$<30$ & 1 \\
\hline $31-40$ & 7 \\
\hline $41-50$ & 9 \\
\hline $51-60$ & 6 \\
\hline $61+$ & 1 \\
\hline Total & 24 \\
\hline
\end{tabular}

\section{Results}

Typical triple cases of breast carcinomas may first be abridged thus:

a) Case No. 3 UH 2064/90. Mostly strikingly, there is a cribriform pattern seen in adenoid cystic carcinoma. Then there is frank frond-like picture of papillary carcinoma. Furthermore, there is an area in which clumps of tumour cells float as it were in mucin.

b) Case No. 22.990243. The appearances are malignant and variable. Most areas show invasive ductal type while adenoid cystic and papillary forms are discernible. c) Case No. 23. 990284. Mostly invasive ductal carcinoma picture is present but there are focal areas of mucoid degeneration and of cribriform formation.

\section{Discussion}

A Siena review[8] on 1158 cases of breast cancer probably provides the correct background regarding "The biological and clinical significance of multifocal and multicentric (MF/MC) breast cancers and the choice of appropriate surgical treatment for these tumors are still debated." Accordingly, I have selected the distinct group that consists of patients whose biopsy specimens exhibited three distinct histological primaries. I am persuaded that their true trend has been documented above.It is evident that the "multiple" type may not be separated from double or triple varieties "[9]". Moreover, multiple primary tumors may imply the combination of breast and other organs [10] The present study applies solely to the breast. Incidentally, the Siena group[8] defined multiplicity in terms of the quadrants of the breast. However, this study shows that even one slide can exhibit up to three varieties of growths! Incidentally, some generalizations may be made. The peak age of incidence is from 41 to 50 years. Most of the operations were carried out in the Cosmopolitan Enugu where Dr. Ojukwu proved to have done half the operations. Surprisingly, left sided growths preponderated in 
the ratio of $4: 1$. The commonest cell type was the invasive ductal carcinoma (20 times) and the least was squamous carcinoma (once).

\section{References}

1. Onuigbo WIB (2015) The surgical pathology of cancer: A historical review. J Cancer Prev Curr Res 2(3): 00039.

2. Jacyna LS (1988) The laboratory and the clinic: The impact of pathology on surgical diagnosis in the Glasgow Western Infirmary, 1875-1910. Bull Hist Med 62: 384-406.

3. Onuigbo WIB (1970) Joseph Coats (1846-99) of Glasgow and the theory of cancer metastasis. Scott Med J 15: 281-284.

4. More IAR, Sandison AT (1973) Triple carcinoma of the breast, one arising within a fibro-adenoma. J Pathol 109(3): 263-265.

5. Onuigbo WIB (1962) Multiple carcinoma of the lung. Br J Dis Chest 56:144-146.

\section{ISSN: 2574-1241}

DOI: 10.26717 /BJSTR.2018.06.001348

Wilson IB Onuigbo. Biomed J Sci \& Tech Res

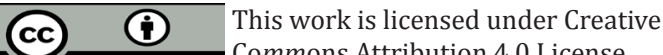

Submission Link: https://biomedres.us/submit-manuscript.php
6. Basden GT (1966) Niger Ibos. Cass, London, UK.

7. Macartney JC, Rollaston TP, Codling BW (1980) Use of a histopathology data pool for epidemiological analysis. J Clin Pathol 33: 351-353.

8. Neri A, Marrelli D, Megha T, Bettarini F, Tacchini D, et al. (2015) Clinical significance of multifocal and multicentric breast cancers and choice of surgical treatment: a retrospective study on a series of 1158 cases. BMC Surg 15:1.

9. Haddow AJ, Boyd JF, Graham AC (1972) Multiple primary neoplasms in the western hospital region, Scotland: A survey based on cancer registration data. Scott Med J 17(4): 143-152.

10. Schottenfeld D, Berg J (1971) Incidence of multiple primary cancersIVCancers of the female breast and genital organs. J Natl Cancer Inst 46(1): 161-170.

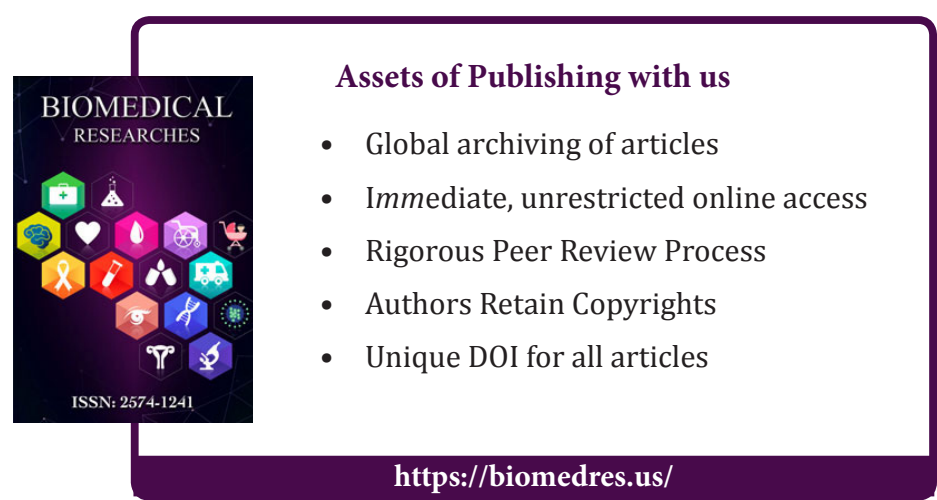

